\title{
HYGIENIC CAGES FOR RATS AND MICE
}

\author{
J. A. LONG \\ Anatomical Laboratory, University of California \\ TWO FIGURES
}

The following is a brief account of cages recently constructed for the Department of Anatomy of the University of California for housing colonies of rats and mice.

In planning these cages the desirability was kept in mind of so designing them that not only might the animals be cared for conveniently, but the cages be easily cleaned and completely sterilized and the spread of infection prevented. Accordingly they were made entirely of metal: the sides and front of galvanized iron, the former preventing the direct passage of infection from cage to cage; and the lid, top, back, and floor of hardware cloth of $\frac{1}{4}$-inch mesh bound with strips of galvanized iron. They can be taken apart, packed in a small space for boiling, and reassembled quickly without the use of any screws or bolts. All parts are interchangeable. The inside dimensions are: floor, $9 \frac{1}{2}$ by $14 \frac{1}{2}$ inches; height 11 inches; front $2 \frac{3}{4}$ inches high.

They are arranged in groups of 20 (4 rows of 5 each, fig. 1). Each group is supported by a rack made of iron pipe, and 4 pairs of angle irons on which the 4 rows of cages are hung. Below each row is placed a shallow, removable, galvanized iron pan intended to be filled with sawdust for receiving refuse falling through the bottoms of the cages. The racks measure $6 \frac{1}{2}$ feet in height, $17 \frac{1}{2}$ inches in depth, and $4 \frac{1}{2}$ feet in width. There is a space of $9 \frac{1}{2}$ inches between the lowest pan and the floor, and 3 inches between the floors of the cages and pans. If desired the racks can be continued upward to carry one or more additional rows.

Most of the details of construction can be seen in figure 2 which shows some of the cages taken down. It will be observed that the sides are suspended and in turn furnish support for the rest of the cage except the top. The sides are put into place by slipping the flanges on the upper edges into grooves ( $g r$ fig. 2) formed by bendingunder the edges of strips of galvanized iron (st). A projection (pr) prevents sliding the sides in too far. The ends of the strips forming the grooves are bent up and over the angle irons and are permanently fastened by means of bolts. These strips also have soldered to their upper sides grooves $(\mathrm{lg})$ opening laterally formed by strips of metal bent in the form of a narrow trough. Into the latter slide the tops to which the lids are hinged by two rings. The backs when in place 


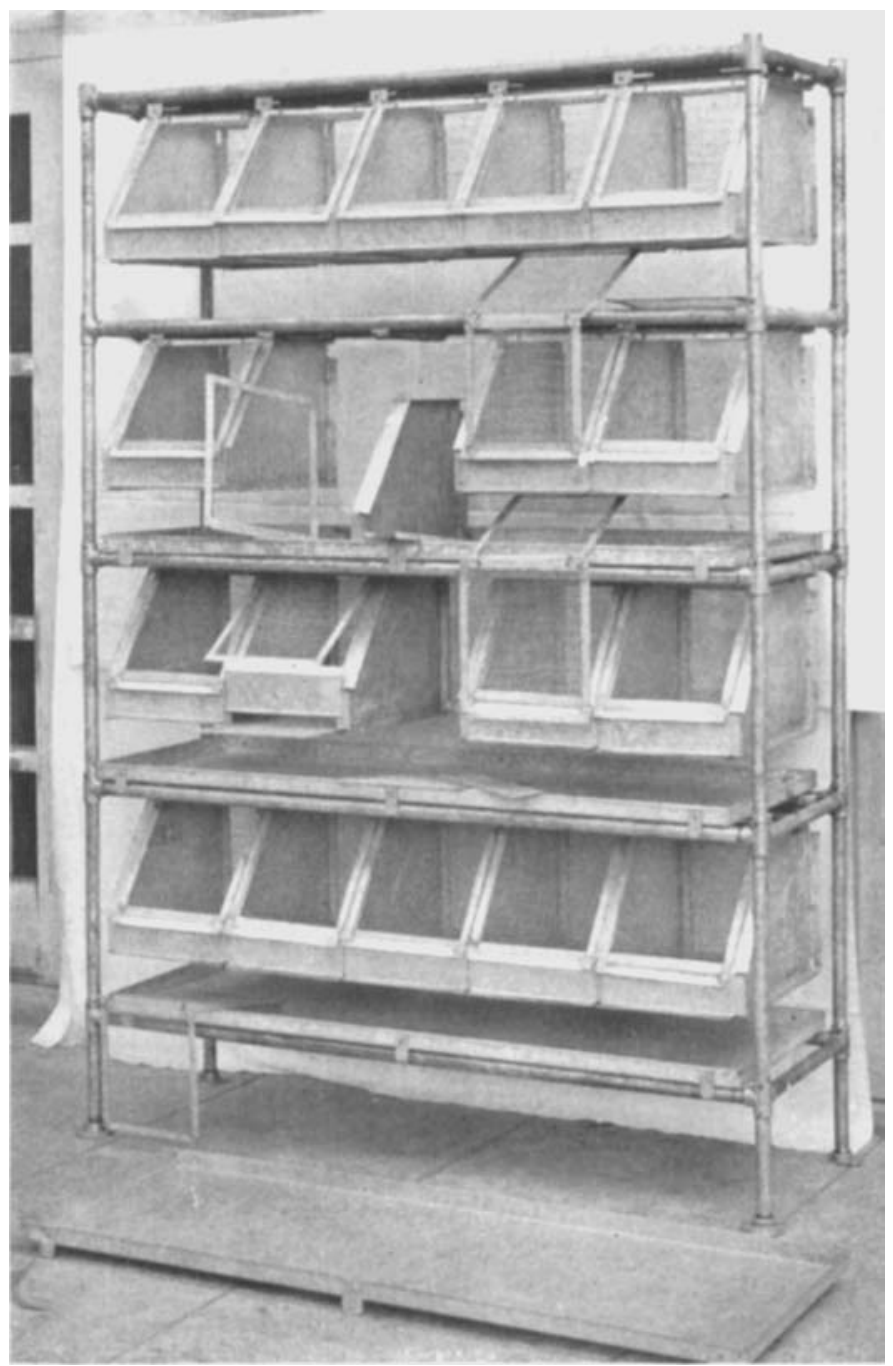




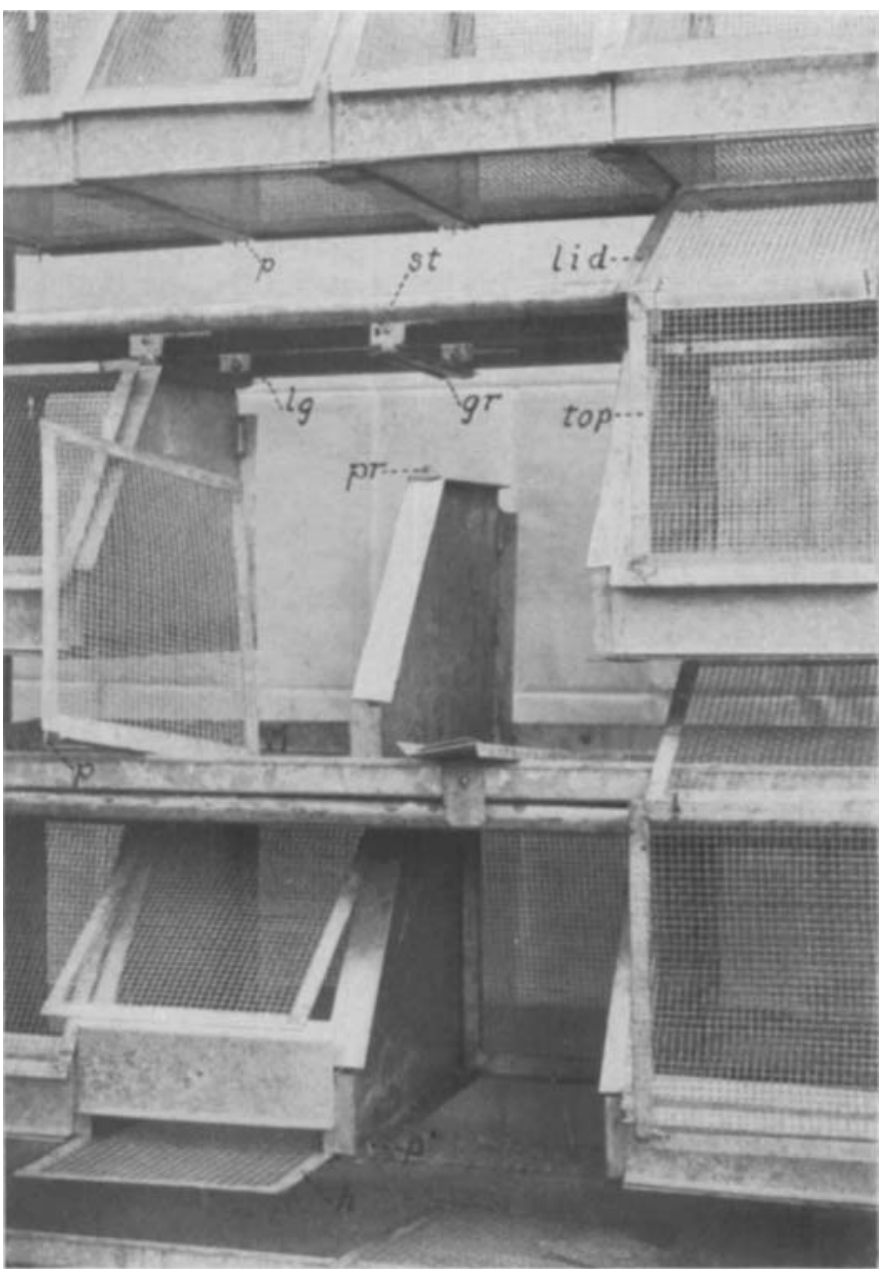


rest on the flanges on the lower edges of the sides and against the front faces of the back flanges. The upper ends of the backs are held firmly because they pass behind the rear angle irons; at the lower ends pins (p) fit into holes in the bottom flanges (the pins can also be seen on the under side of the upper row of cages). The binding on the lower edgo of each back is turned forward at a right angle and together with the flanges on the lower edges of the sides serves to support the floor. The latter are kept in place by two pins $\left(p^{\prime}\right)$ which fit into corresponding holes $(h)$ in the binding. The front is made of one piece of metal. One may be seen endwise resting on the edge of a tray. The ends are bent somewhat in the from of a letter $S$ to form troughs which fit over the flanges on the front edges of the sides.

In assembling the cages the sidos are first put into place, then the backs, floors, front, and top (with lid). It will be seen that the floors may be changed without disturbing the rest of the cage, or by removing simply the front. A number of extra bottoms makes it possible to clean one set and have them ready to substitute for soiled ones every week. The other parts of the cages need cleaning only at longer intervals.

For the cages used for rats, flools of $\frac{1}{2}$ inch mesh are provided.

It has been found in actual breeding that 4 and even 6 adult rats can be kept in one cage, and as many as 10 or 12 young rats raised to breeding age in single cages.

The construction of this equipment was worked out by Prof. H. M. Evans and the writer with assistance from Mr. H. B. Foster, the University Engineer. 